\title{
Evaluating Major Problems of MA Students of TEFL in Developing Proposals: MA Students and Their Professors' Perceptions in Focus
}

\author{
Halesadat Abhari \\ English Department, Najafabad Branch, Islamic Azad University, Najafabad, Iran \\ Hadi Salehi (Corresponding author) \\ English Department, Najafabad Branch, Islamic Azad University, Najafabad, Iran \\ Email: hadisalehi1358@yahoo.com
}

Received: 24/04/2021

Accepted: 03/08/2021

Published: 01/09/2021

Volume: 2 Issue: 5

How to cite this paper: Abhari, H., \& Salehi, H. (2021). Evaluating Major Problems of MA Students of TEFL in Developing Proposals: MA Students and Their Professors' Perceptions in Focus. Journal of Critical Studies in Language and Literature, 2(5), 32-37

DOI: https://doi.org/10.46809/jcs1l.v2i5.85

DOR: https://dorl.net/dor/20.1001.1.27324605.2021.2.5.5.3

Copyright (C) by author(s) and Global Talent Academy Ltd. This work is licensed under the Creative Commons Attribution International License (CC BY 4.0).

http://creativecommons.org/licenses/by/4.0/

$$
\text { (c) (i) }
$$

\begin{abstract}
This study aimed at evaluating the major problems of MA students of TEFL in developing proposals from the viewpoint of MA students and their professors. This quantitative study enjoyed a descriptive method and presented the frequencies and percentages of the analyzed data. The participants were a sample of 40 MA students of TEFL and 15 professors. They were requested to fill out a separate valid and reliable 40-item questionnaire. These two questionnaires were designed to evaluate students' viewpoints about writing proposals and professors' viewpoint about students' proposals. Since the obtained data were non-parametric, Chi-square test was applied to analyze the data. The findings showed that APA style was not completely taught to MA students. The students had enough familiarity with the layout and physical appearance, and had appropriate knowledge of skills and subskills; however, they did not know how to analyze the data. Professors also believed that students could not explain the implications of the study perfectly in their proposals and could not provide a complete reference section. They also believed that students were not able enough to use cohesive devices. On the other hand, the difference between MA students and professors regarding the issue of affective factors was not statistically significant. The findings of this study will be useful for professors who teach seminar courses, and the administrators of the universities to offer acceptable format for the proposals, and to make students more aware of principles they should follow in proposal writing to submit an acceptable proposal.
\end{abstract}

Keywords: Evaluation, Proposal, MA TEFL Student, Perception

\section{Introduction}

Writing a good English composition or essay seems never very easy. It requires the ability of assessing a good grammar, imagination and thought, exploring major, and supporting ideas, putting them together, and revising them as the final editing Younes and Albalawi (2015, p.27).

Students' weaknesses in writing motivate the researcher to do this research. All TEFL MA students are supposed to 
a proposal, so that they should have enough familiarity with its content and format. This study aimed to help students in preparing an acceptable proposal that follows some principles; it should have the appropriate content and format based onthe Publication Manual of the American Psychological Association (APA) writing style.

The purpose is to find major problems of MA students of TEFL in writing proposals, including both format and content, from students and professors' viewpoint. This study was conducted to help MA students know their weaknesses in writing proposals, and let them know how to avoid them. The findings of this study might be helpful to MA professors who teach seminar courses, it also helps the administrators of the university to offer acceptable format for the proposals, and to make students more aware of principles they should follow in proposal writing to submit an acceptable proposal.

Proposals are going to present and justify the need to study a research problem and to present practical ways in which the proposed study is going to be conducted. Design elements and procedures for conducting any types of research are governed by standards of the predominant discipline. Furthermore, a proposal describes methodology for conducting a research and includes some different sections which are governed by standards of the predominant discipline (Krathwohl, 2005).

Good proposals provide suitable answers for the following questions; what does the researcher want to do, and how does he/she plan to do it? How much will it cost, and how much time will it take? What has already been done in the area of the project? Why should the researcher choose this topic? How will the collected and the results be evaluated?

Main parts of proposals are introduction, literature review, research design and method, conclusion, and references. The opening part of the proposals is an introduction which includes significance of the research problem. The literature review is a deliberate review of prior studies related to the research problem under investigation. Next section is about the research design and method.

The previous paragraph was about the content. As it was mentioned before, both format and content of proposals will be evaluated during this study. It should be mentioned that format of the proposals should be based on APA writing style which is the most common style used for proposals related to the social sciences. This writing style has its specific style for title, abstract, main body, citations, and references. In the next chapter, there are more elaborations of APA style.

All in all, the aim of the study is to find out the major problems and help them avoid their weak points in developing proposals, including both format and content, from their viewpoints and their professors' viewpoints in order to make students more aware of the principles they should follow in proposal writing.

\section{Literature Review}

To date, a great number of studies have been performed on students' writing. In this case we considered proposal writing and reasons behind students' weakness in writing proposal. Dastjerdi and Samian (2011) claimed that Iranian EFL learners have frequent cohesion problems that show their poor knowledge of English cohesion rules, as well as their poor linguistic awareness, especially in syntactic and semantic areas. Similarly, Shokrpour and Fallahzadeh (2007) mentioned that learners of English as a foreign language face with problems and challenges such as vocabulary, grammar, spelling, and punctuation. Moreover, Hosseini et al. (2013) submitted that EFL learners' weakness in English proficiency influence their writing skill which is a necessary skill to convey their knowledge, especially for academic purposes.

Generally speaking, Khany and Abol-Nejadian (2010) found out three stages of doing and writing research that are considered as very complex issues for Iranians. These issues are pre-preparation, preparation, and post preparation stages. They reported, team work, leadership, intrinsic motivation and the weak English knowledge as the main difficulties encountered in the first stage. In the preparation stage, the accuracy of expression, variation on vocabulary, and appropriate structures, and problems of plagiarism are the main concerns. Post preparation problems are mainly related to publishing the results in journals and articles.

Some scholars believe that among all skills of learning a second language, the most complex and challenging one is writing. Writing is based on appropriate and strategic use of language within a structured and communicative pattern (Dar and Khan, 2015; Hyland, 2003; Kellogg, 2001, and Mahboob 2014). Writing is a complex cognitive process which needs memory, thinking ability, and verbal command in order to express the ideas successfully (Geiser \& Studley, 2002; Hyland 2003; McCutchen, 1984, and Nickerson, Perkins, \& Smith, 2014).

Academic writing is very important and students should know how to write. Academic writing is used as a tool for conveying meaning, having effective communication of ideas, and doing research works (Dar \& Khan 2015; Graham \& Perin 2007; Haider 2012, and Hyland, 2003). Yugianingrum (2010) identified some characteristics for a good academic writing. The first one is that the writing should play a significant role in its relevant community. A good writing should have a good topic which is interesting for the writer, who believes that there is more to discover about it. The last characteristic is that the writer must also care about the aesthetic quality of the text he/she writes (Yugianingrum, 2010).

There are plenty of challenges in writing students face with. Various writing problems at different stages of learning might occur, even for postgraduate students. Generally, these problems can be classified into linguistic, psychological, cognitive, and pedagogical (Haider, 2012 and Hyland, 2003).

Other points of view remark that, writing is usually difficult for students because the lack of interaction, which works as stimulator in oral production and conversation (Maesin, Mansor, Nayan, Osman, and Shafie, 2010). Sometimes students' confident is not enough. Having enough self- confidence is a must in writing and low self-confidence makes writing harder for the students (Ahmad et al., 2013). Furthermore, lack of knowledge and certain necessary skills for writing among non- 
native speakers of English add difficulty to the process of writing. Some of these skills involve outlining, paraphrasing, and summarizing.

\section{Research Questions}

Q1. What are MA students of TEFL viewpoints about their major problems in writing proposal?

Q2. What are professors' viewpoint sabout MA students of TEFL major problems in writing proposal?

Q3. Is there any significant difference between TEFL professors' viewpoint and MA students' viewpoint regarding to students' problems in writing proposal?

\section{Method}

\subsection{Design}

This quantitative study enjoys a descriptive method. It should be mentioned that a quantitative research design deals with quantifying and analyzing in order to get results. Aliaga and Gunderson (2002) described quantitative research method as the explaining of an issue or phenomenon through gathering data in numerical form, and analyzing with the aid of mathematical methods. Furthermore, according to Williams (2011), quantitative research starts with a statement of a problem, generating of hypothesis or research question, reviewing related literature, and a quantitative analysis of data.

For the sake of clarity, the method of conducting the research which is quantitative and descriptive method was elaborated completely. Furthermore, in this survey two types of questionnaires and interviews were conducted.

\subsection{Participants}

The participants of this study were selected from the university of Isfahan, Najafabad University, and Khorasgan University. All MA students are majored in TEFL. It should be mentioned that our participants are not English literature or English translation students. Five professors and 15 MA students were selected from each mentioned universities, so the whole participants of this study were 15 professors and 45 MA TEFL students, and they were chosen based on their availability.

\subsection{Instruments}

Two types of instruments were used to perform this study questionnaire and interview.

Two sets of questionnaires were developed by the researcher, using Five-Point-Likert Scale method. Each included 40 items. The reliability and validity of questionnaires were proved and they were piloted on a group similar to the sample of the study, which had five members. Moreover, interviews were conducted at the end of the study in order to get the story behind the participants' experiences to have further investigation of their responses. Two interviewees were conducted in each of the above mentioned university, an interview with a professor and the other with an MA student.

\subsection{Procedure}

The procedure of this study was as the following order. Selecting the participants was the first stage of the study. The participants were MA students and their professors; who were selected from University of Isfahan, Islamic Azad University, Najafabad Branch, and Islamic Azad University, Khorasgan Branch. The participants of this study were 15 professors and 40 MA TEFL students and they were chosen based on their availability.

Two sets of questionnaires were provided by the researcher, one for the MA students and the other one for the professors. The questionnaires were verified after the observation of three professors, then piloted in a group similar to the main group of the study in order to determine the validity. Cronbach Alpha formula was used to determine the reliability of the questionnaires. Then interviews were conducted with the participants and the results were recorded in order to compare MA students' viewpoint and the professors' to get the conclusion.

\subsection{Data Analysis}

In order to analyze the statistical data of this study, Statistical Package for the Social Sciences (SPSS) software was used by the researcher. In order to answer the research questions, frequency and percentages were calculated and represented through tables and figures.

Chi-squared test was also used for the received data of the questionnaires. The Chi Square statistic is commonly used for testing relationships between variables. We also got benefit from the Chi-squared test to compare the results of the questionnaires in order to see if there is a relationship between the MA students' result and the professors' results of the questionnaire.

\subsection{Discussion and Conclusion}

The findings reveal that, according to students' viewpoints, they were familiar with the size of the margins of the paper, they knew how to organize main headings and subheadings of a proposal, but did not know how to analyze the data. Students also claimed that they have enough familiarity with the layout and physical appearance of a thesis proposal.

About the content of a proposal students mentioned that they can not take advantage of the most appropriate instruments for their research, but they knew how to choose participants for their study, they were familiar with different types of research designs, they were also able to provide appropriate key terms with their definitions for their proposals.

Regarding to skills and subskills, student respondents agreed to some extent that they had appropriate word choice for writing the proposal, that they could use grammatically correct sentences in their proposal texts, they could apply punctuation and capitalization appropriately in their writings. 
About the affective factors that are very important students contended that their professors did not motivate them in writing proposal and confessed that they were not good risk takers because they did not like to be judged. They also believed that their professors used outdated methods of teaching writing and thus they were not eager to learn. Students also claimed that they were not confident enough when they were asked to write a proposal.

Fareed (2016) stated that low ability and writing anxiety of students were pressured by some factors like, having untrained writing instructors, ineffective teaching methods of writing, insufficient system of writing examination, lack of reading and writing practice, big classes, low motivation, and limited ideas. Other than that, as Ismail et al., (2010) believed, apprehensive in writing activities and negative attitude toward academic writing also become factors that determine EFL students' difficulties in writing. It is obvious that writing is a difficult skill even for graduate students (Bailey, 2003; Fareed et al., 2016; Setyowati \& Sukmawan, 2016). Therefore, these problems should be solved in order to improve EFL students' ability in writing.

On the other hand, the professors expressed their disagreement with the claims that students were familiar with the size and margins of the paper. They stated that students did not know how to use appropriate tables and figures in their proposals, and do not know how to give in-text citations according to the APA referencing style. Students also did not know the appropriate length of each section of the proposal in professors' viewpoint. Professors believed their MA students were familiar with sampling techniques, knew how to choose participants for their studies, and could develop appropriate content for their proposals.

Furthermore, professors disagreed that students knew how to analyze the data, that students knew how to express the novelty of their study so as to occupy the niche in previous research. Professors also believed that, students could not explain the implications of the study perfectly in their proposals, and could not provide a complete reference section. They also mentioned that students were not able enough to use cohesive devices and were not able to use most language subskills in proposal writing. It indicates that TEFL professors believed MA students lacked the skills and subskills required to write a thesis proposal.

Professors' viewpoints about affective factors in proposal writing were exactly opposite of the students' viewpoints. They believed that they have motivated students to write a proposal, and used updated and appropriate methods of teaching writing. Professors stated that writing classes are not crowded and uninteresting.

All in all, professors agreed that their students were familiar with the layout and physical appearance of a proposal, but did not have enough familiarity with the contents. They firmly disagreed with the negative remarks pertinent to affective factors, though not to a significant degree. Generally speaking, students face major problems in three ways namely grammatical, punctuational, and spelling problems. Further findings showed that there are several other reasons which contribute to students' weaknesses in writing.

Beside students' low ability in writing aspects, they have lack of writing practice, low writing motivation, negative writing perception, time limitation in conducting the writing test, and lack of writing courses. Basically, these facts appeared on the students' reasons because of their negative perception of writing. Therefore, students experience writing anxiety (Fareed et al., 2016; Huwari \& Aziz, 2011; Kurniashi, 2013; Wahyuni \& Umam, 2017). The factors that cause writing anxiety of EFL students are difficulties in linguistics, worry of teachers' negative comments, inadequate writing technique and practice, lack of topic knowledge, and time pressure (Kurniashi, 2013; Wahyuni \& Umam, 2017).

Byrne (1988) stated that the nature of writing process is a complex process because it requires the mastery of grammatical devices, conceptual thinking, and judgmental elements. Byrne classifies the writing complexities into three categories; psychological, linguistic, and cognitive problems. Moreover, Nunan (1989, p.36) wrote the following concerning the difficulty of writing:

Writing is an extremely complex cognitive activity; in which the writer is required to demonstrate control of a number of variables simultaneously. At the sentence level these include control of content, format, sentence structure, vocabulary, and punctuation. Beyond the sentence, the writer must be able to structure and integrate information into cohesive and coherent paragraphs and texts.

Clifford (1987) believed that learners of English as a second or foreign language also face problems of exploring ideas and thought to communicate with others; in other words, they have content problem in speaking and writing. According to Leki (1991), this could be because of the traditional methods teachers use to teach writing for spelling, punctuation, and mastering grammar. Clifford (1987) also suggested that teachers should encourage students to focus on the message, ideas or thoughts they want to convey rather than grammar, spelling, punctuation, and other elements. Raimes (1983) stated that the other problem of organization in student' writing is the difficulty of differentiating a topic and supporting ideas and specific details. Pincas (1982) has also showed that learners have the problems of writing united paragraphs because of their failure to use cohesive devices appropriately.

Regarding layout and physical appearance, there was a significant difference between the viewpoints of MA students and TEFL professor. There was also a significant difference between these two groups of participants with regard to their viewpoints about contents and also skills/subskills needed for writing a proposal. In contrary, the difference between MA students and TEFL teachers regarding the issue of affective factors was not found to be a statistically significant one.

These differences may be due to the facts that students are not experienced enough in writing, professors do not motivate students to write, and students are not asked to write some samples before writing the proposal. 
It can be concluded that MA students' considered themselves familiar with content and layout, and to some extent proficient in skills and subskills needed to write a proposal. They agreed with the existence of negative forces affecting their proposal writing practices, but not to a significant extent.

TEFL professors believed that their students were familiar with the layout of a proposal but not to a significant degree. They also believed that their MA students did not have enough familiarity with the contents of proposals. Professors claimed that most of the students have mastery over the skills and subskills. Additionally, they disagreed with the existence of negative forces pertinent to affective factors, though not to a significant degree.

Regarding layout, contents, and skills/subskills, there were significant differences between the viewpoints of MA students and TEFL professors. However, the difference between MA students and TEFL teachers regarding the issue of affective factors was not found to be a statistically significant one.

\section{References}

Ahmad, N., Khan, F. N., Munir, N., et al. (2013). Factors affecting the learning of English at secondary school level in Khyber Pakhtunkhwa, Pakistan. International Journal of English Language and Literature Studies, 2 (2), $95-101$.

Aliaga, M. and Gunderson, B. (2002) Interactive Statistics Thousand Oaks, Sage Publications.

Allen. (2004). Assessing Academic Programs in Higher Education by Al-Shabanah \& Maher. (2005).

Bailey, S. (2003). Academic Writing: A Practical Guide for Students. Cheltenham, U.K.: Nelson Thornes Ltd.

Dar, M. F., \& Khan, I. (2015). Writing anxiety among public and private sectors Pakistani undergraduate university students. Pakistan Journal of Gender Studies, 10 (1), 121- 136.

Dastjerdi, H., \& Samian, H. S. (2011). Quality of Iranian EFL learners' Argumentative Essays: Cohesive Devices in Focus. Mediterranean Journal of Social Sciences, 2(2), 2011, 65-76.

Fareed, M., Ashraf, A., \& Bilal, M. (2016). ESL Learners' Writing Skills: Problems, Factors, and Suggestions. Journal of Education and Social Sciences, 4(2), 81-92.

Geiser, S., \& Studley, w. R. (2002). Predictive validity and differential impact of the SAT I and SAT II at the University of California. Educational Assessment, 8 (1), 1-26.

Graham, S., \& Perin, D. (2007). Writing next-effective strategies to improve writing of adolescents in miO’Malley, J. M., \& Chamot, A. U. (1990). Learning strategies in second language acquisition. Cambridge University Press, United Kingdom. The Elementary School Journal, 94 (2), 169-181.

Alexa Kellogg, R. T. (2001), Mahboob, A., \& Talaat, M. (2008). Long-term working memory in text production. Memory \& cognition, 29 (1), 43-52. ndria, USA.

Khany, Reza and Abol-Nejadian, Rezvan (2010), Iranian post-graduate students academic research article, Teaching English Language, Science research. ISC.

Krathwohl, David and Smith, Nick (2005), How to Prepare a Dissertation Proposal, Syracuse, New York: Syracuse University Press.

Kurniashi, K. (2013). EFL Writing Anxiety: Level, Types, and Causes. Malang: Maulana Malik Ibrahim State Islamic University of Malang in cooperation with Naila Putake Inc.

Haider, G. (2012). An insight into difficulties faced by Pakistani student writers: Implications for teaching of writing. Journal of Educational and Social Research, 2 (3), 17-27.

Hosseini, M., Taghizadeh, M. E., Abedin, M. J. Z., \& E. Naseri. (2013). In the Importance of EFL Learners' Writing Skill, International Letters of Social and Humanistic Sciences, 6(1).

Huwari, I. F., \& Aziz, N. H. A. (2011). Writing Apprehension in English among Jordanian Postgraduate Students at University Utara Malaysia (UUM). International Academic Research, 1(2), 190-198.

Ismail, N., Elias, S., Albakri, I. S. M. A., Perumal, P. D., \& Muthusami, I. (2010). Exploring EFL Students' Apprehension Level and Attitude towards Academic Writing. International Journal of Learning, 17(6), 475-484.

Lona Leki, (1991). Foreign Language Annals, volume24, issue3 The preferences of ESL Students for Error Correction, Wiley publication.

Maesin, A., Mansor, M., Nayan, S., Osman, N., \& Shafie, L. A, (2010). Understanding Collaborative Academic Writing Among Beginner University Writers in Malaysia. Studies in Literature and Language, 1, 58-69.

McCutchen, D. (1984). Writing as a linguistic problem. Educational Psychologist, 19 (4), 226-238.

Nickerson, R. S., Perkins, D. N., \& Smith, E. E. (2014). The Teaching of Thinking. Routledge, United Kingdom.

Shokrpour, N., \& Fallahzadeh, M. H. (2007). A Survey of the Students and Interns' EFL Writing Problems in Shiraz University of Medical Sciences. The Asian EFL Journal Quarterly, 9(1).

Nunan, D. (1989). Designing Communicative Tasks and Activities. Oxford: Oxford University Press. Page: 36.

Setyowati, L., \& Sukmawan, S. (2016). EFL Indonesian Students' Attitude Toward Writing in English. Arab World English Journal, 7(4), 365-378.

Wahyuni, S., \& Umam, M. K. (2017). An Analysis on Writing Anxiety of Indonesian EFL College Learners. Journal of English Education and Linguistic Studies, 4(1), 103-126.

Williams, C. (2011). Research methods. Journal of Business \& Economics Research (JBER), 5(3). 
Yugianingrum. (2010). Producing an English Academic Paper: Process, Problems, and Solutions. US-China Foreign Language, 8, 39-49.

Z. B. Younes and F. S. Albalawi, (2015). Exploring the Most Common Types of Writing Problems among English Language and Translation Major Sophomore Female Students at Tabuk University," Asian J. Basic Appl. Sci., vol. 3, no. 2, pp. 23 